\title{
Structure, Effects and Deficiencies of an Entrepreneurial Ecosystem: the Spanish Case
}

\author{
José Manuel Comeche-Martínez \\ comeche@uv.es \\ Universitat de València \\ José Vicente Pascual-Ivars \\ jose.pascual@uv.es \\ Universitat de València \\ Salvador Vivas-López \\ svivas@valencia.edu \\ Universitat de València
}

\begin{abstract}
In this paper, we rely on the Spanish GEM Project to analyze the basic conditions that shape the profiles of the Spanish regional entrepreneurial ecosystem and to configure which aspects are given and which should be met in order for that ecosystem to be considered as a tool to support entrepreneurship and not just a wasteland. Although some media are incorporated, the nutrients needed for germination are not included.
\end{abstract}

\section{Keywords:}

Entrepreneurship, Entrepreneurial Ecosystem, GEM. 


\section{Introduction}

"Game over." Thurik (2007) raised the necessary transition from a command economy (secure and good jobs, economies of scale, stability, homogeneity, continuity, etc.) to an entrepreneurial society (Audretsch, 2007) based on concepts such as flexibility, novelty, originality, creativity, and diversity. Marina (2013) reports on the growing interest in the concept of learning: "Learning to undertake to innovate and to teach. In a fast society, subjected to constant innovation, we have to learn throughout our entire life." In this new and demanding economy inserted into an innovative and creative society, "entrepreneurial" activity is the central core. However, its development requires an enabling environment that provides key nutrients to ensure that entrepreneurial seed germinates. The basic minimum conditions required in that environment shape the socalled entrepreneurial ecosystem.

In this paper, we rely on the Spanish GEM Project to analyze the basic conditions that shape the profiles of the Spanish regional entrepreneurial ecosystem and to configure which aspects are given and which should be met in order for that ecosystem to be considered as a tool to support entrepreneurship and not just a wasteland. Although some media are incorporated, the nutrients needed for germination are not included.

In previous years (2012), business opportunities in Spain, although good, were not adequately exploited by business agents, businessmen or entrepreneurs, and the business succession was insufficient. This contrasts with the strong wave of vibrant entrepreneurial drive, especially among youth who demand lower entry barriers, efficient regulation, less administrative supervision, better conditions for carrying out the activity and direction of economic globalism based on principles of competition, efficiency and international competitiveness and demands that the administration should provide appropriate care. On the other hand, we must not forget the serious economic crisis that our country has suffered for years; in most cases, it has discouraged entrepreneurial initiatives, because even if the entrepreneurial individual defies the negativism generated by the economic crisis, the mood conditions the economy. However, in order to create an entrepreneurial ecosystem that generates positive changes on a permanent basis, companies have to take into account that entrepreneurship is not a heroic act by a few individuals but rather the actions of many people who are dedicated to pursuing their ambitions in an environmental, institutional and cultural environment "that helps".

\section{Entrepreneur Ecosystem. Concept}

The RAE (Real Academia Española) explains the term Ecosystem as a "Community of living beings whose vital processes are related to each other and are developed according to the physical factors of the same environment"; as we can see below, in the development of the Tech Innovation Ecosystem of Silicon Valley, the interactions of the different actors in the environment are oriented to contribute in the development, empowerment and survival of companies: 


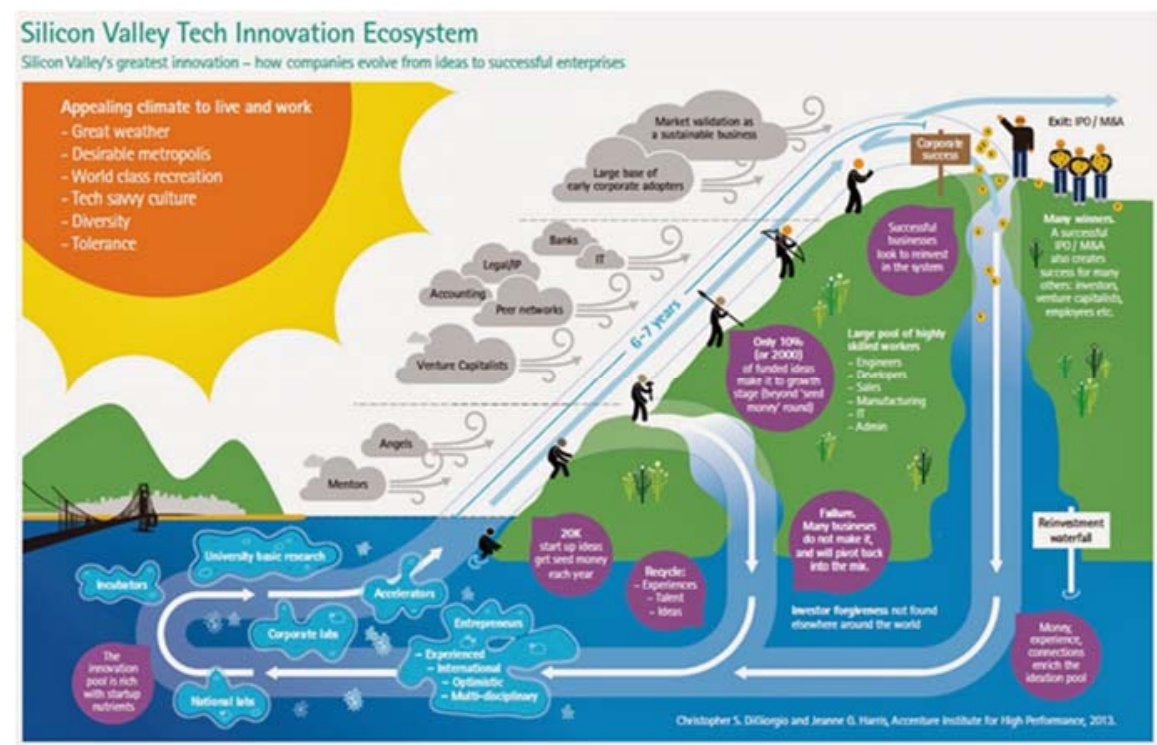

Source: Accenture 2013. High Performance. Delivered

Meanwhile, according to the Economic and Finance Dictionary (Tamames, 1995), the term ecosystem refers to "a set of characteristics of a living space, in which the medium and the different populations are related, with reciprocal interactions". Therefore, if we relate both ends with the term entrepreneur, the concept "entrepreneurial ecosystem" refers to all entrepreneurs who develop their skills in particular physical and environmental surroundings.

Although there are many definitions of an entrepreneurial ecosystem, they all incorporate references to the combination of any of the following elements: people, institutions, the media and/or physical resources.

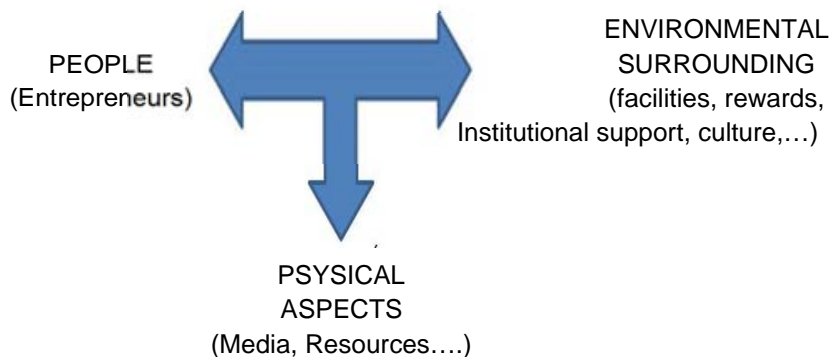

Here are some of them:

"A set of complex relationships between entities and entrepreneurs with their technology, academic, social, political and economic environments; stimulating the development of entrepreneurial initiatives (M-607) ${ }^{1 "}$.

The stimulating nature of the ecosystem as a driver of entrepreneurial initiatives once again is denoted.

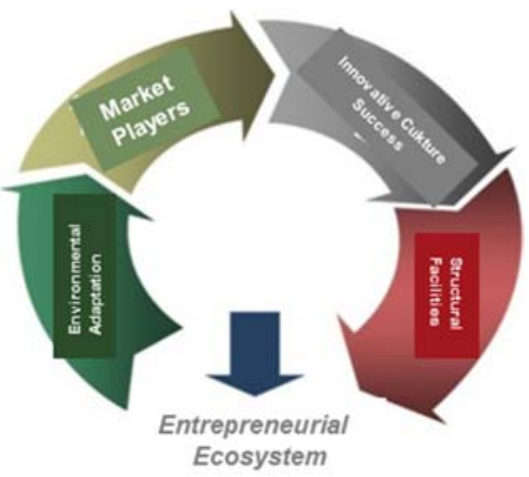

Source: Ministerio de Industria, Turismo y Comercio 2013. 
${ }^{1}$ The M-607 Project started as an initiative of the Ministry of Industry, Tourism and Trade, which launched a program to encourage cooperation between existing support centers for entrepreneurs in 2010.

How do they generate ecosystems identified as entrepreneurial? The answer seems clear: public institutions are those that have the ability to design the social changes needed to drive the cultural changes that would welcome the ecosystem. In fact, we will show some examples of our claim by moving to our country, specifically and initially to the Community of Madrid. According to the General Policy Direction of SME, under the General Secretary of Industry, the first step is to ask a series of questions (Annex I) that may suggest basic cultural changes to our relationship with the environment. In this case, a program designed to complement the efforts of public and private entities inspires the creation and development of these centers so that they can design a more specialized approach suited to the profiles and needs of entrepreneurs2. The approach is based on the need to change the production model in our economy, a fact that has reached a consensus point in our society. To this end, universities, public bodies, the financial and private sector, consumers and all those who in one way or another influence their generation must unite their capacities and initiatives to provide creative solutions that materialize the words into facts.

At the same time, because we all look to entrepreneurs as an important part in the search for the new production model, the project promoters M-607 have joined up to create an "entrepreneurial ecosystem", understanding "action to undertake" as an evolutionary process that begins when the idea arises and ends when it reaches its maximum development and not merely as the action of starting a project. Thus, entrepreneurship is viewed as a chain process in which each link is a different stage of the project, such that progress in the chain reflects the increased maturity of the project, transforming gradually from a diffuse initial idea to an established company.

Graphically:

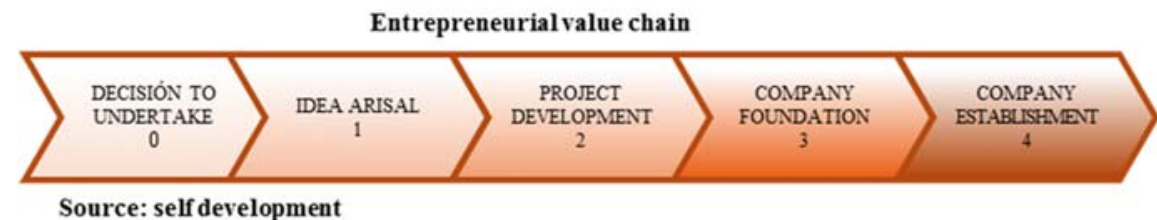

Performances, collaborations, and services offered to entrepreneurs vary at each point depending on the project's maturity.

That is,

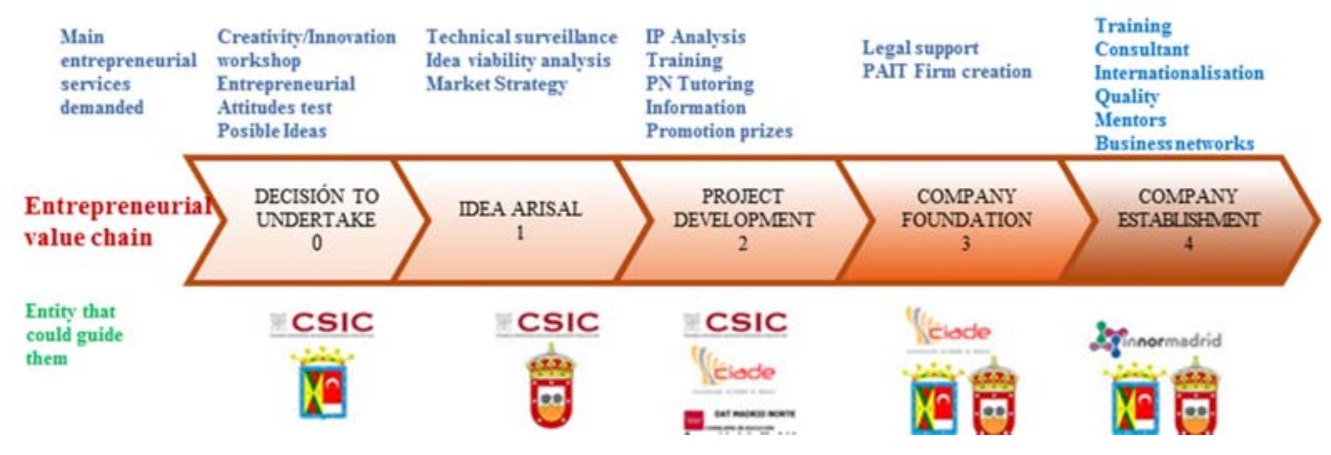


${ }^{2}$ The Eco-System Entrepreneur Project M-607 is developed around the M-607 highway, and has vocation for permanence, as it is part of a Higher Project: the Campus of International Excellence UAM + CSIC. This project has a vocation of growth towards a second axis, the M-616, and towards the City of Madrid.

However, this predisposition to define, design and fertilize the field of the entrepreneurial ecosystem is not optional for this community. As an example, we can incorporate another local scenario (Valencia) that aims to show who is who in the Valencian entrepreneurial ecosystem:

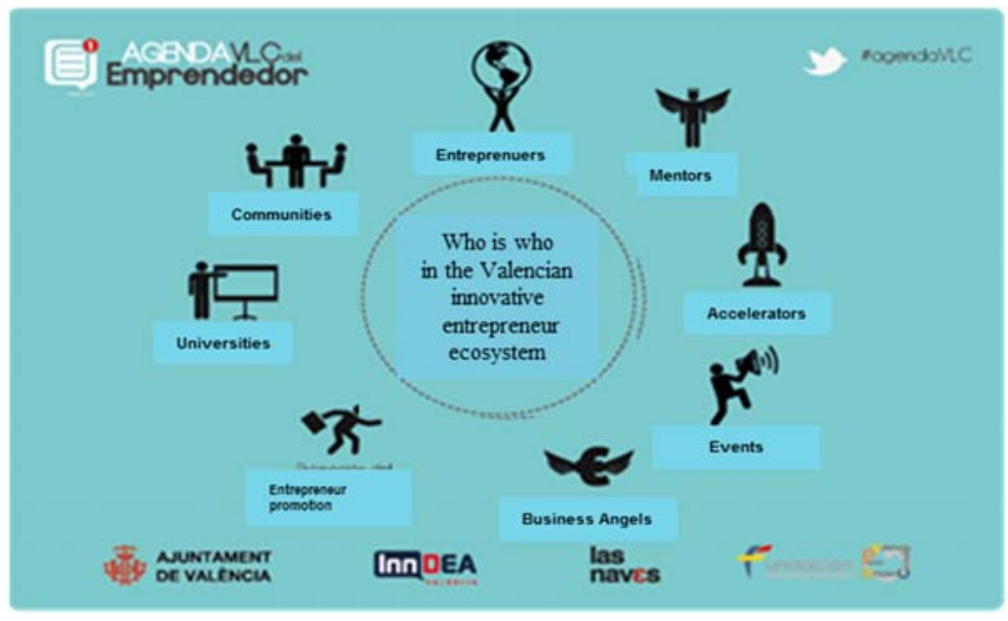

In the same sense, a higher body operates. We present the outline obtained from the "Generalitat of Valencia" that reflects the different partners that the Entrepreneur Project requires depending also on their degree of maturity:

However, if we exceed our borders and move our research to other Latin American

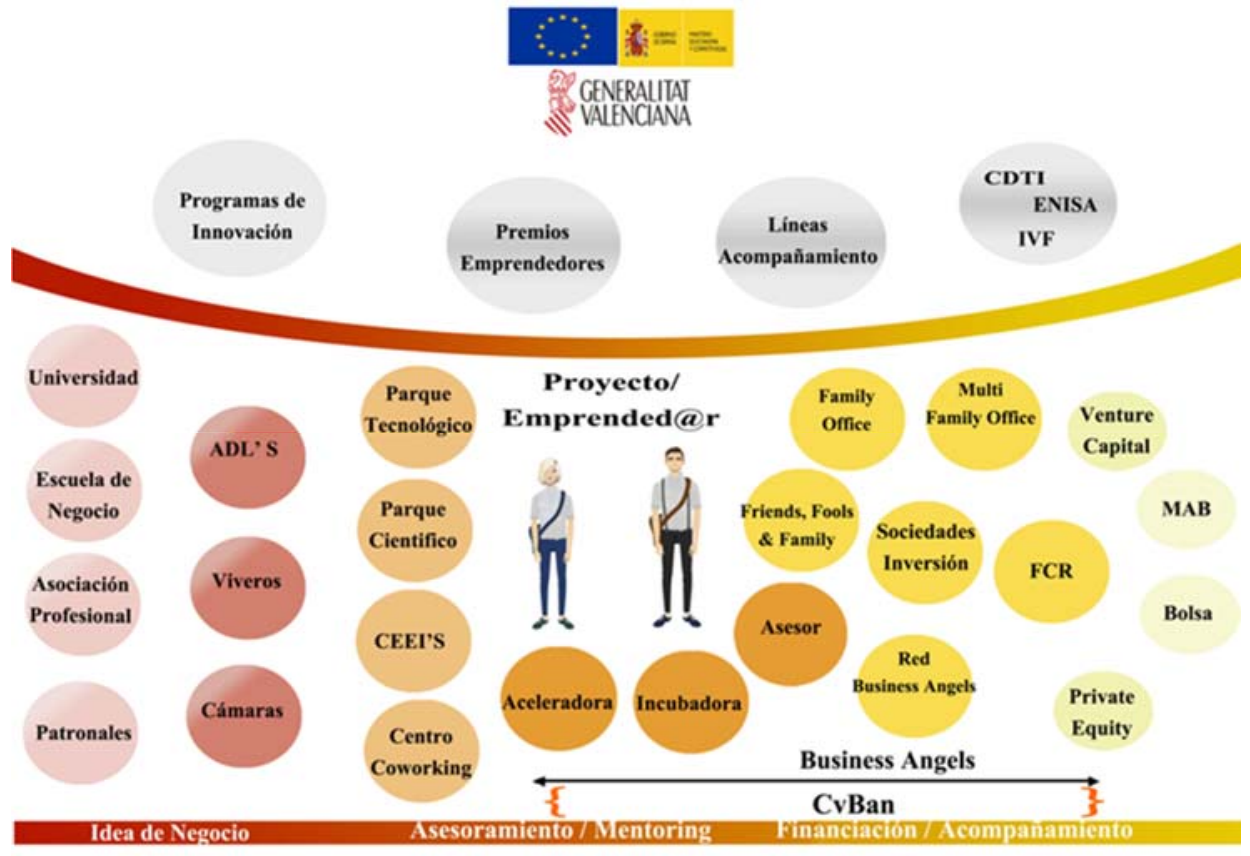

countries such as Mexico, we observe something similar. Mexico innova provides a scheme, similar to the previous one and even slightly more complete, although it correlates with different environments in its effort to raise awareness of the participants' roles and actions in the Entrepreneurial Ecosystem: 


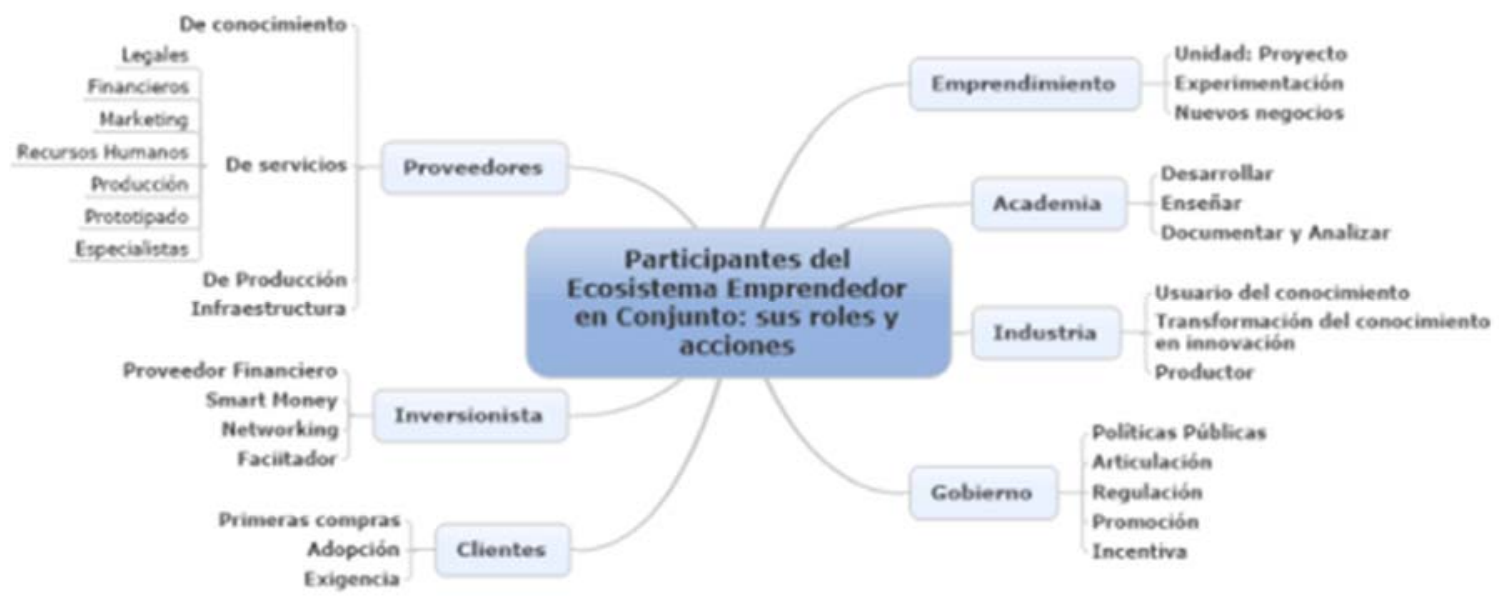

We can present more examples of the generation and composition of an entrepreneurial ecosystem using, as an example, the Strategic Technology Observatory (OET), which is also in Mexico:

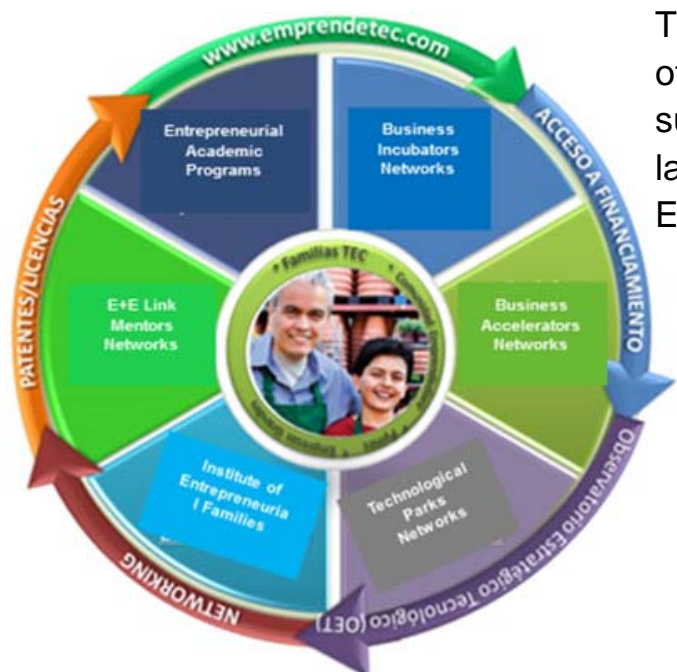

This time with more emphasis on the establishment of cultural change from the beginning, i.e., care and support to other more established concept in these latitudes, the family, in our case: Entrepreneur families and/or TEC families.

As we can see, there are countless examples of contributions of entrepreneurial ecosystems, designed more towards one direction or another depending on their promoters and intentions and objectives for their development, but as we announced at the beginning, all of them share three characteristics, the environmental environment, the physical environment and the main element, without which there would be no entrepreneurial projects, which is the generation of an entrepreneurial culture that encourages the emergence of entrepreneurs. In our work, we have concluded that, in order to shape this characterization, we needed to combine the influence of at least four elements, namely:

\section{People.}

2. The Public function.

3. Financial Market.

4. Universities.

We will analyze each of them. 


\section{Elements of Influence in the Development of Entrepreneurial Ecosystems: The People.}

We accept that the "entrepreneurial process" is a process that starts with the generation of an idea, continues with the implementation actions, launches, enters a consolidation phase and moves to the consolidated phase when it survives for more than 3.5 years. Another possible destination is the abandonment of the promoter, either to pass the initiative into other hands or to permanently close (GEM_2013). In this process, for the year 2013 , we observe an increase of $2.1 \%$ in the percentage of the Spanish population that perceives opportunities to undertake.

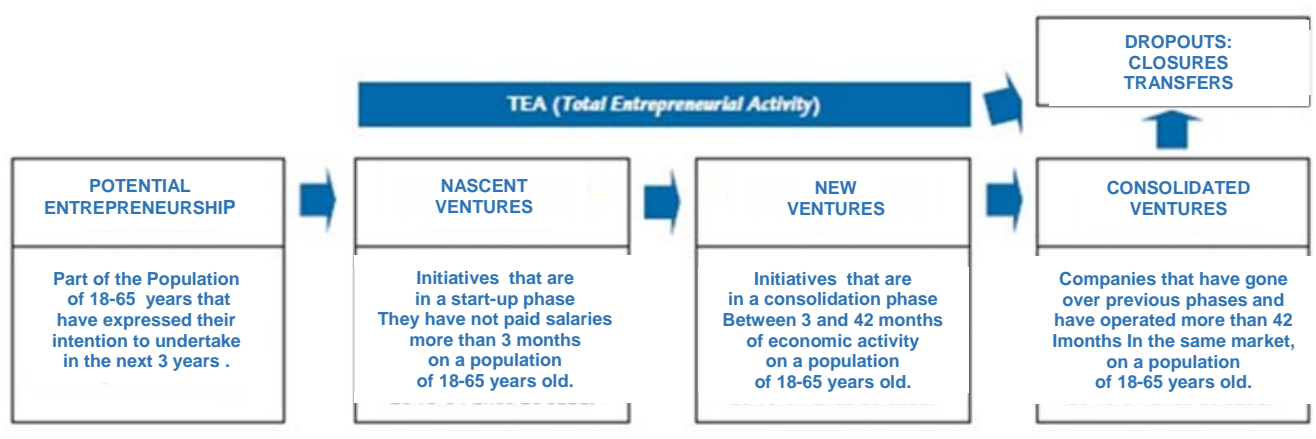

This is an important fact, although we cannot find such results since 2010 . However, it is not only the recognition of opportunities that encourages entrepreneurs to take the initiative; some individual characteristics also play an important role. We have selected some of the most relevant as follows:

a) The Self-recognition. Understood as the belief that we have the abilities, capacities and competencies needed to create a business or conduct any entrepreneurial activity:

\begin{tabular}{ll}
2012 & 2013 \\
\hline $50,4 \%$ & $48,4 \%$
\end{tabular}

Although there is a difference of two points over the past year, the trend is maintained. See graphic 1.

It seems clear that they have served as facilitators in maintaining such tendency as vital elements for the promotion of entrepreneurial activity and strengthening of the individual capacities: the role of the education system, job training and previous experiences.

b) The assessment of the feasibility of exploiting a business opportunity, i.e., the degree of fear of failure as an obstacle. Understood as the perception of these obstacles and the ability to address them.

$2012 \quad 2013$
$53,0 \%-47,7 \%$

It is evident that more than half of the Spanish population surveyed perceives a HIGH RISK at the time of undertaking. See graphic 2 . 
c) The existence of reference models as a reinforcing element for the individual because knowing or contacting entrepreneurs helps the candidate know the problems of the entrepreneurial process, even to lay the foundations for collaboration and development of possible networks that support entrepreneurship.

$\frac{2012}{31,1 \% \quad 30,8 \%}$

The indicator shows that approximately $1 / 3$ of the population surveyed claims to know an entrepreneur who has created a company in recent years. See graphic 3.

d) Clear perception of culture and its influence on entrepreneurship as essential elements in individuals' decision-making about socio-cultural aspects associated with entrepreneurship. The GEM_2013 has taken into account aspects such as "opinion on equity in living standards in Spain," the "view that entrepreneurship is a good career option", the "view that undertaking provides social and economic status in Spain" and the "evolving views on the diffusion of entrepreneurship is carried out in the media" to design an index to show the impact of culture SUPPORT TO ENTREPRENEURSHIP in every society.

As we see, the indicator shows a slight decrease in the index for 2012.

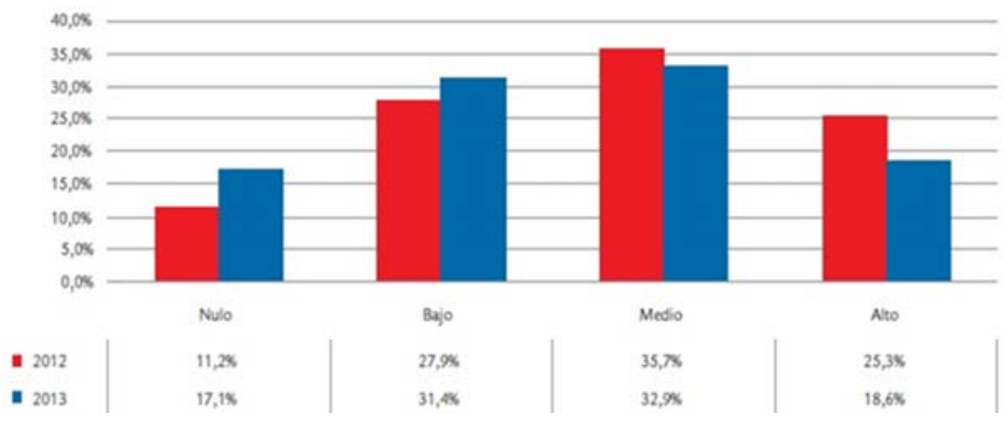


Regarding the possible comparison between Spain and other EU countries (who have participated in the GEM_2013), data confirm that the Spaniards are below average in terms of the perception of opportunities, the existence of reference models, the opinion that the venture has a "good career option" or "provides social and economic status"; as well as on the role of the media in publicizing the successes of new companies and new entrepreneurs.

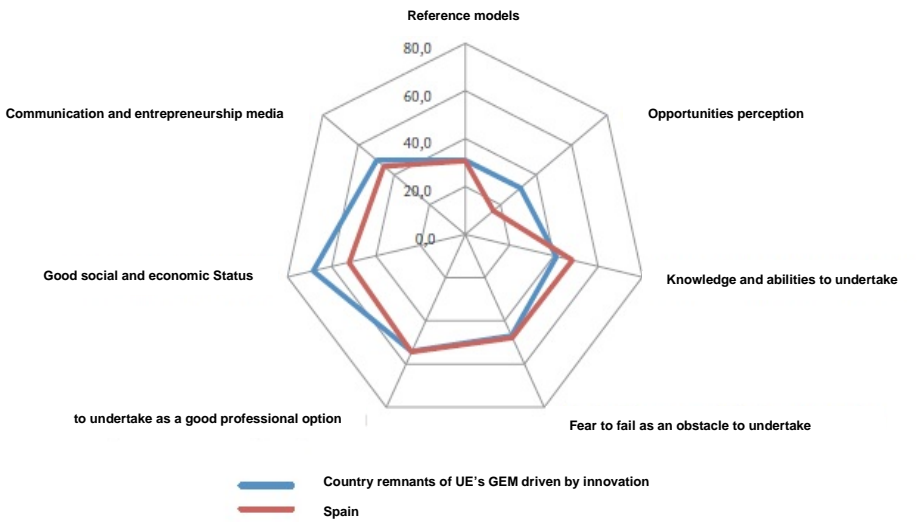

Source: GEM 2013. Perceptions, values and attitudes of Spaniards compared to the rest of the EU in 2013.
However, perceptions of Spaniards concerned with selfknowledge among those who have the knowledge, skills and competencies

necessary undertake concerned with the fear to fail, they are above the average.

For all of the above, we suspect that Spanish society DOES consider that it has the capabilities required to carry out an entrepreneurial action without considering the possibility of failure as an impediment to starting a business.

Therefore, why is the Spanish $\operatorname{TAE}^{3}$ so low (5.2\%)? According to experts interviewed in the GEM_2013, the main environmental conditions that hinder the entrepreneurial action include government policies and access to finance, as well as education and entrepreneurial training at school age.

\begin{tabular}{|c|c|c|c|c|c|c|c|c|c|c|}
\hline Environmental Conditions & 2005 & 2006 & 2007 & 2008 & 2009 & 2010 & 2011 & 2012 & 2013 & Situación \\
\hline Innovation assessment: consumer & & & & 3,46 & 3,25 & 3,60 & 3,35 & 3,47 & 3,97 & Mejora \\
\hline Access to psysical and services infrastructure & 3,64 & 3,61 & 3,56 & 3,54 & 3,67 & 3,61 & 3,46 & 3,98 & 3,91 & Estable \\
\hline Gobernment programms & 3,01 & 3,17 & 3,13 & 3,10 & 3,06 & 2,49 & 2,72 & 2,79 & 3,05 & Mejora \\
\hline Support to female entrepreneurship & & 3,18 & 3,30 & 3,11 & 3,32 & 2,81 & 3,01 & 3,13 & 2,91 & Empeora \\
\hline Innovation assessment: Firm & & & & 3,09 & 2,90 & 2,68 & 2,62 & 2,79 & 2,86 & Mejora \\
\hline Support to high potential grow & 3,05 & 3,06 & 3,04 & 3,02 & 3,15 & 2,54 & 2,66 & 2,92 & 2,72 & Empeora \\
\hline Intellectual property assessment & 2,89 & 2,83 & 2,92 & 2,76 & 2,81 & 2,65 & 2,57 & 2,51 & 2,61 & Mejora \\
\hline Access to comercial and professional Infrastructure & 3,26 & 3,18 & 3,23 & 2,98 & 3,06 & 2,86 & 2,58 & 3,04 & 2,53 & Empeora \\
\hline Gobernment policies: priority and support & 2,69 & 2,84 & 2,90 & 2,73 & 2,60 & 2,40 & 2,06 & 2,68 & 2,34 & Empeora \\
\hline Barriers to internal market access & 2,70 & 2,97 & 2,76 & 2,60 & 2,68 & 2,30 & 2,16 & 2,46 & 2,28 & Empeora \\
\hline Entrepreneurial Education and training (post stage) & 2,75 & 2,82 & 2,82 & 2,81 & 2,65 & 2,26 & 2,34 & 2,34 & 2,25 & Empeora \\
\hline $1+D$ transfer & 2,52 & 2,51 & 2,53 & 2,60 & 2,42 & 2,24 & 2,13 & 2,34 & 2,19 & Empeora \\
\hline Internal Market Dynamic & 2,16 & 2,29 & 2,09 & 2,40 & 2,50 & 2,55 & 2,69 & 2,79 & 2,14 & Empeora \\
\hline Social and Culturl rules & 2,74 & 2,69 & 2,74 & 2,80 & 2,45 & 2,27 & 2,21 & 2,34 & 2,11 & Empeora \\
\hline Gobernment Policies: Burocracy and taxes & 2,81 & 2,79 & 2,80 & 2,56 & 2,34 & 2,21 & 2,21 & 2,59 & 2,01 & Empeora \\
\hline Fiancing for Entrepreneurs & 2,54 & 2,57 & 2,67 & 2,58 & 2,20 & 2,08 & 2,06 & 2,06 & 1,79 & Empeora \\
\hline $\begin{array}{l}\text { Entrepreneurial Education and Training (school } \\
\text { stage) }\end{array}$ & 1,87 & 2,01 & 2,00 & 1,91 & 1,73 & 1,58 & 1,56 & 1,52 & 1,37 & Empeora \\
\hline
\end{tabular}

${ }^{3}$ TAE or TEA: Total Entrepreneurial Activity. It is calculated as the ratio (\%) among the adult population, owners or founders of start-ups that have survived in the market for a period of at least 3.5 years. 


\section{Elements of influence in the development of entrepreneurial ecosystem: the public function.}

In 2013, an initiative was launched by the Spanish government to support entrepreneurial activity; approved by the Congress of Deputies, it is called the Support Law for Entrepreneurs and their Internationalization.

Overall, the main actions of the law are aimed at the following:

a) Supporting entrepreneurial activity and strengthen the entrepreneurial culture.

b) Providing support measures, particularly related to tax and social security.

c) Providing tax incentives and financial support for SMEs.

d) Promoting the birth and development of entrepreneurial projects.

e) Promoting internationalization

This is intended as a basis of contribution to improve environmental conditions and the strength of an entrepreneurial ecosystem in Spain.

In a first analysis, we can conclude that, despite existing efforts, the effectiveness of government policies, taxation ${ }^{4}$ and bureaucracy is not enough to boost the birth and development of companies in Spain in the near future. The economic scenario is complicated by the various cuts in public budgets and by uncertainty in financial markets, making it increasingly difficult to access credit through the various institutions, despite efforts such as outright grants, grants for business creation and the operation of Business angels networks.

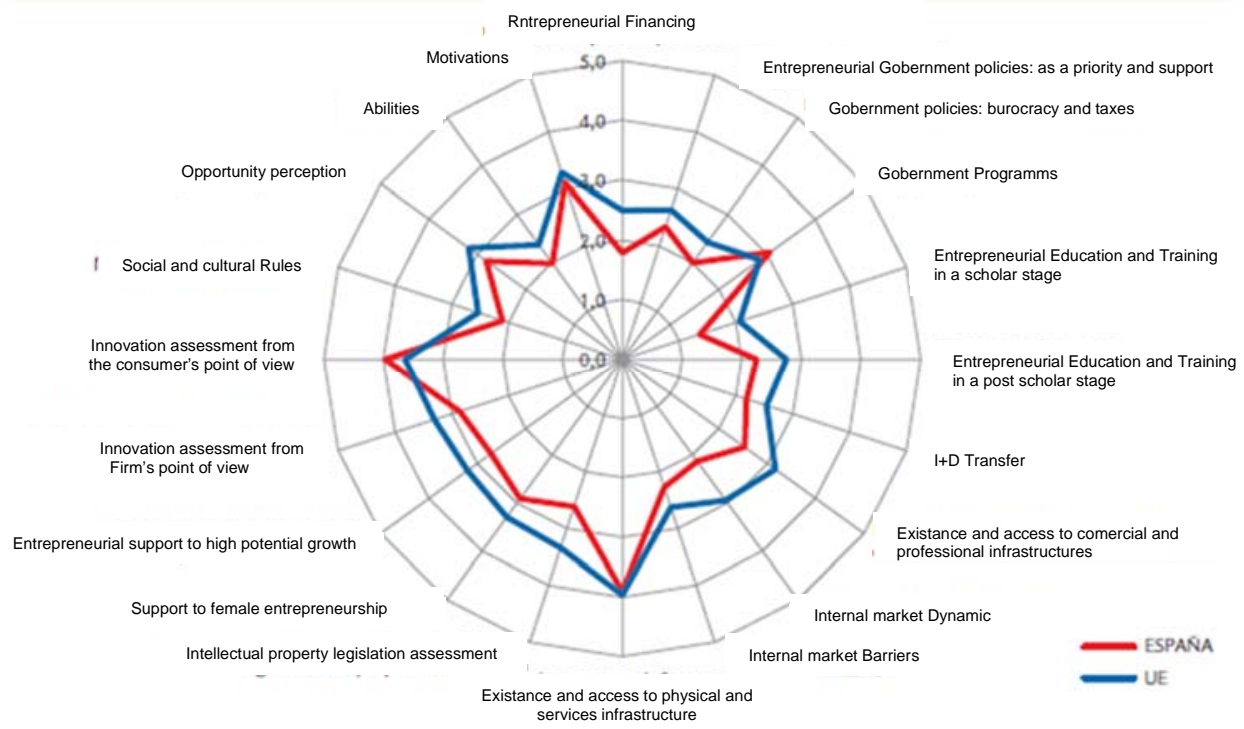

Source: GEM 2013. Average rating on the conditions of the environment to undertake in Spain

\footnotetext{
${ }^{4}$ According to the 2013 Paying Taxes Report, published jointly by PWC and the World Bank, the total tax burden of companies (e.g., contributions to the SS and IS) in Spain rose to approximately 58\% of pre-tax income, thereby positioning the country as the third highest European economy with higher taxes for companies (PWC, 2013).
} 
In this regard and as a breeding ground necessary for the generation of an entrepreneurial ecosystem, the cultural hub is one of the conditions of the specific environment that decisively influences entrepreneurial activity. In this regard, studies on economic growth show that, in times of economic recession, the effect on entrepreneurial activity is ambiguous (Audretsch \& Thurik, 2001). Although some authors (Evans \& Leighton, 1990) found that the highest levels of unemployment served as a catalyst for the creation of enterprises, others (Audretsch \& Fritsch, 1994) found that unemployment reduces the amount of entrepreneurial activity.

It is therefore interesting to consider the opinion of Spanish experts (Guerrero and Urban, 2011) who continue to recommend education and training as a major source of innovative human potential and entrepreneurship capable of rejuvenating and transforming the Spanish business fabric. We have noted a third aspect to consider, education and entrepreneurship training during the school stage, which they maintain as one of the outstanding issues.

Along these lines, strengthening entrepreneurial spirit and reducing psychological and cultural barriers in the early stages of the entrepreneurial process should be targeted, through different educational levels and even through entrepreneurial educational training programs. This raises the following question: do the existing pathways, designed to support entrepreneurship not consider these aspects? It seems that they do not, possibly because in the last decade, much of the budgetary support for entrepreneurship has focused primarily on the business creation stage and, to a lesser degree, on awareness and consolidation. This would justify the shortsighted approach of such measures and the myopia of our leaders bent on quick results as an element of political justification. This forces us to return to the aforementioned Support Law for Entrepreneurship, in its attempt to enact a series of considerations to promote entrepreneurial spirit in primary, secondary, job training and university education. If the law is consolidated, the results could be expected in the medium and long term regarding the identification of opportunities and entrepreneurial skills. However, the overall assessment offered by the experts consulted by the GEM_2013 regarding the effectiveness prescribed by hat law reaches 3.29 points $^{5}$, not reaching above 3.5 in any category.

However, regarding the law's impact on the environment and analyzing the 12 strategic axes referenced by the GEM_2013 meanings in the table (Annex II), we note that the average rating in this case is even lower (2.85), which reflects widespread skepticism about the Law's ambitious objective to change the structural conditions of the entrepreneurial phenomenon to generate forced entrepreneurial ecosystems.

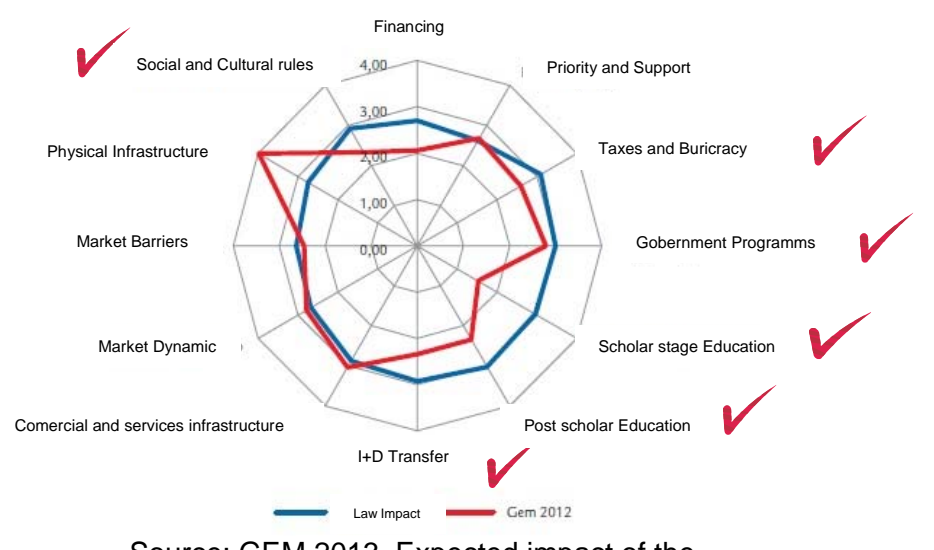

Source: GEM 2013. Expected impact of the Law on the Entrepreneurial Environment.

${ }^{5}$ Based on a Likert scale 1-5. 
As noted in the chart, if we compare it with the valuations of the experts in GEM_2012, timid positive valuation differences in the strategic areas related to education, taxes and bureaucracy, transfer and financing, social and cultural norms and government policies are observed, whereas the rest are negative or virtually nonexistent.

In conclusion, we question whether the goal of "change of mentality in which society values more entrepreneurship and risk-taking" is achievable through the application of a law that lacks the approval of experts, not reaching even the minimum expected effect on the entrepreneurial environment. Its shortcomings include, for example, the need to pay more attention to the early stages and seedbeds of innovative projects and high value-added, creating shared value (Porter \& Kramer, 2011; Sennett, 2012) and the redirection of business objectives to search for more complex sources of competitive advantages. It does not provide the corresponding budgetary resources and dialogue actions and coordination of and with social partners and institutions that address the systemic promotion of the entrepreneurial mindset (Sarasvathy \& Venkataraman, 2011).

\section{Elements of influence in the development of entrepreneurial ecosystem: the financial market.}

Another element to consider in developing an entrepreneurial ecosystem is the existence or absence of venture capital markets. Spain has experienced poor growth, and this has direct implications for the newly established firms segment.

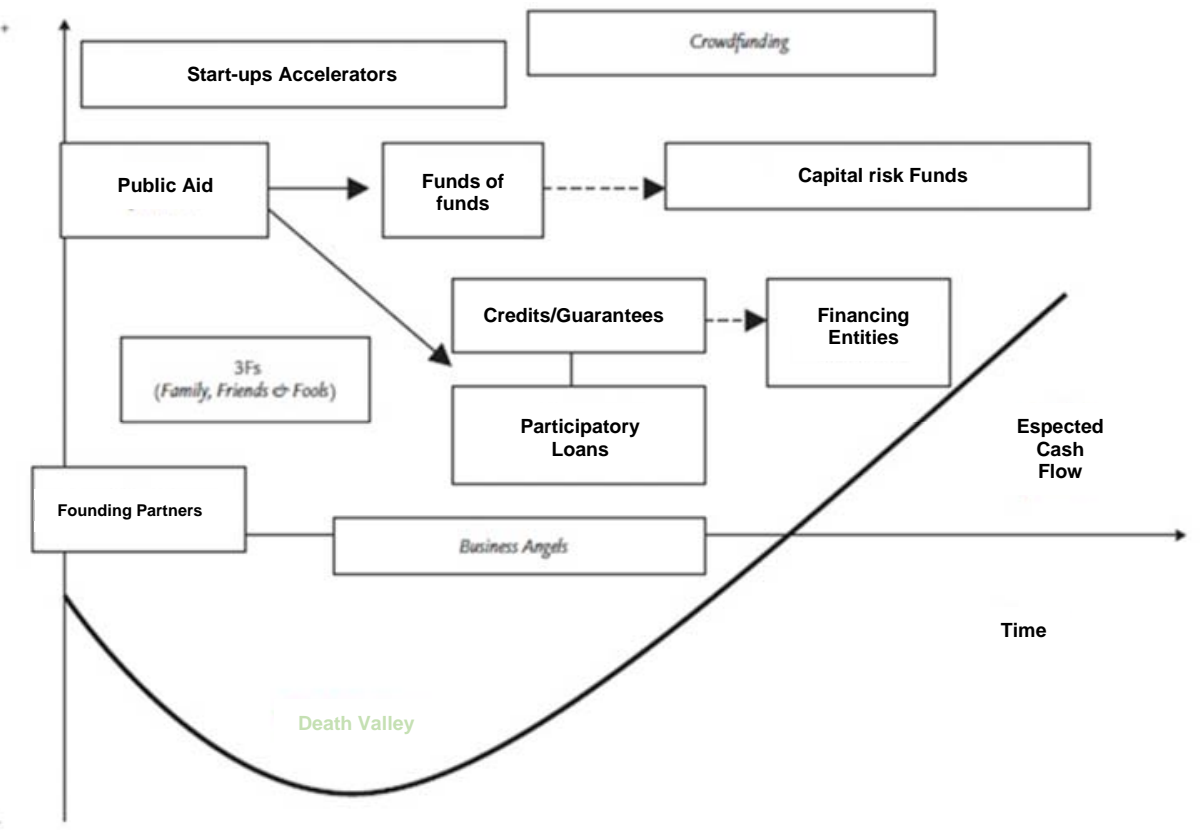

Source: GEM 2013. Source of business funding in the gestation stages (seed and start-up)

It inhibits new business projects with potential from accessing adequate financial resources and shortens the risk level prevailing in the seed and start phases. That is why the informal segment of financing (3F's) acquires an undeniable role in financing the entrepreneurial process of any economy (Mason, 2006). 
In this area, the Business angels play a key role because of their role in reducing the "equity gap"6 (Harrison, et al., 2010, OCDE, 2011). Areas for improvement include designing a more proactive entrepreneurial ecosystem in funding, designing an adequate supply of microcredit and efficiently channeling mediation lines available to the ICO in this regard.

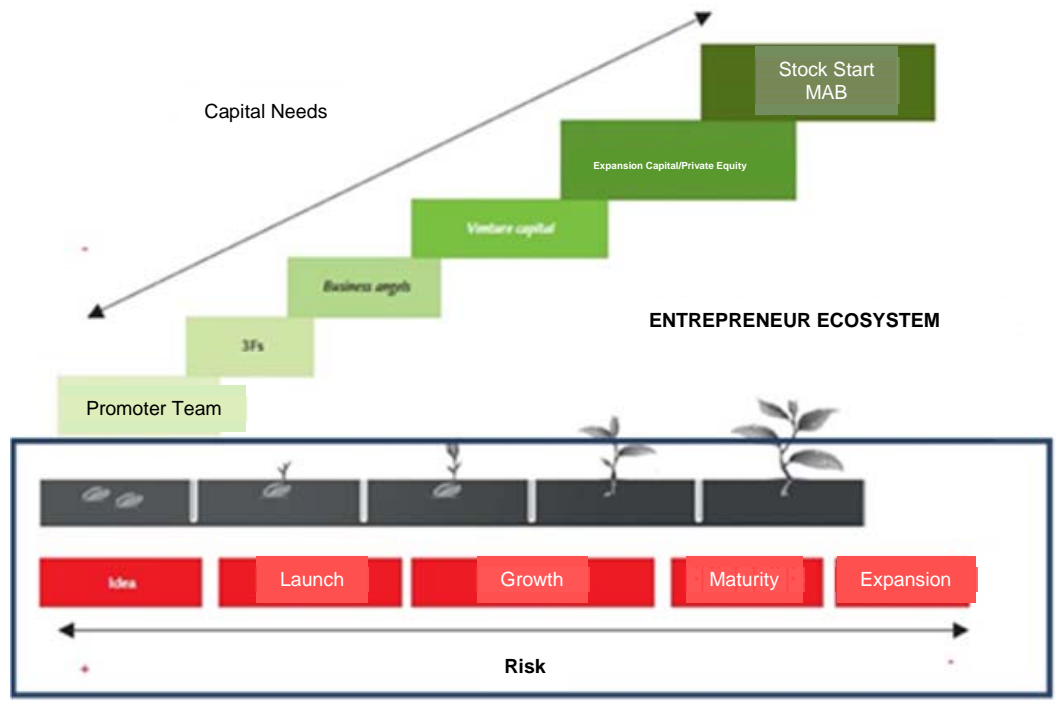

Source GEM 2013 and own source. Secuential process in the finanting of an scalable entrepreneurial project.

At the same time, we assert that the role of business angels must also be enhanced, if possible, either through the improvement and adaptation of the Entrepreneur Support Law (art.26) and through the encouragement of other aspects such as the "partnership" as a means of diversification, risk reduction and knowledge exchange. The concept of "crowdfunding" could also serve as a framework for flexible and transparent intermediation between the business projects and the community, being an excellent introduction channel to investment activity for "inexperienced" investors; this would facilitate the expansion and development of economic and entrepreneurial awareness in a society that pursues its development in a sociocultural entrepreneurial environment. Improving the preparation of entrepreneurs in school is vital so that they understand the inflow of foreign capital into the company because "it is often the case that there is a natural reluctance of promoters teams to share the property, lose autonomy and see diminished their participation (Minola et al., 2008).

${ }^{6}$ Equity Gap: financing gap that appears when start-ups have exhausted their local funds and have not yet been able to resort to bank financing under competitive conditions. 


\section{Elements of influence in the development of entrepreneurial ecosystem: the university}

A fundamental element plays a key role in the generation of cultural change advocated in previous pages: the University. At this point, we echo the report requested by the European Commission on the State of the University-Business Cooperation in Spain ${ }^{7}$ which makes clear the ecosystem model sought (UBC Ecosystem Model) and the various elements that compose it and its influence on the UBC model:
1. Indirect outcome (society)
2. Direct outcome (actors)
3. University-Business
4. Influencing factors Cooperation (UBC) types
5. Supporting mechanisms
6. Key stakeholders

In the detailed model (Annex III), we can see the influences and effects of the various elements and how entrepreneurship is one of the types of UBC sought to generate a complete global ecosystem.

For this study, 8 types of cooperation between the University and the Company (UBC) were recognized:

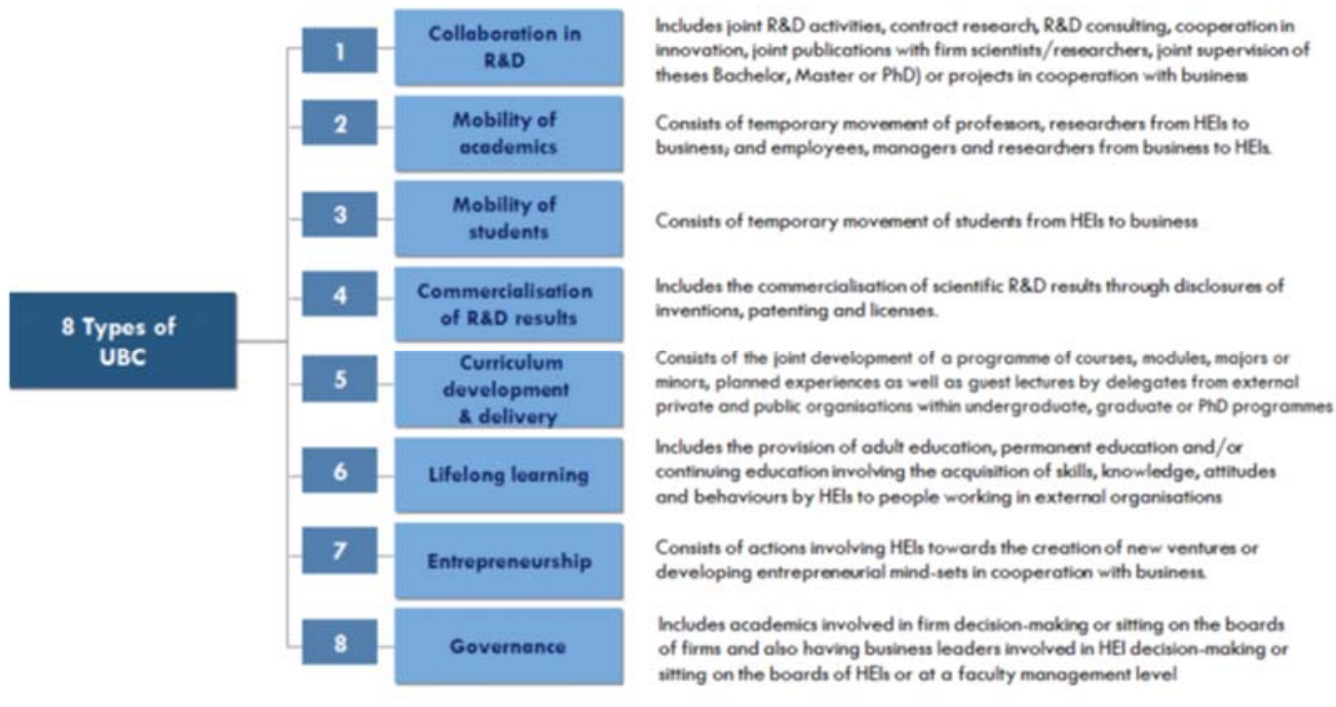

This shows a deep difference in the findings of the actors involved in the study, namely, the Higher Education Institution (HEI) Managers and Academics (A) for cooperation between HEls and enterprises. Hence the term University-Business Cooperation (UBC), since "HEIs" perceive themselves as European leaders at UBC with high level of development of so-called supporting mechanisms. Conversely, "A" (Spanish Academics) perceive that there is a substantial lower level of development of the UBC, especially few implementation strategies. In any case, the following findings of the study are offered:

${ }^{7}$ Science-to-Business Marketing Research Centre, apprimo UG and University Industry Innovation Network (UIIN), 2013.ISBN: 978-90-820668-5-2.

1. The UBC is vital in creating a knowledge society.

2. The UBC generates direct effects on students, HEls, Academics and businesses. 
3. Those types of cooperation with more direct, measurable and promotable benefits, are the most developed (e.g., collaborative R \& D, student mobility).

a. Situational factors (e.g., age) help explain the UBC, but there is little that can be implemented based on these results.

b. Lack of funding and excessive bureaucracy at all levels (HEI, national, European) are determining UBC barriers.

c. Personal relationships lead UBC. It is like a game for people.

d. Perceptions of the Benefits \& Incentives of the High Personnel are motivators of UBC.

4. The creation and development of Supporting Mechanisms (especially those with greatest impact) are critical to the UBC.

5. In the ecosystem of UBC, multiple actors need to work cooperatively and in a coordinated manner.

\section{Conclusions}

After content analysis, accepted structures and effects of different conceptions of an "entrepreneurial ecosystem", we can make the following conclusions:

1) In Spain, the conditions for a more comfortable entrepreneurial environment are given as follows:

a. People are encouraged toward innovation and entrepreneurship.

b. They are able to meet the perceived risks.

c. They begin to take institutional steps to do so.

2) A drastic change is needed in the areas of resources and means. It is necessary to improve the conditions of access to finance.

3) The idea of the entrepreneur must change in the cultural paradigm. Despite the existence of a previous "entrepreneurial identity", evolutionary mental support is necessary to give the first step and should include education in preand post-school stages.

4) Certain elements should be eliminated, including the role of the universities, the wall of impenetrable glass between the training received and the defendant, "the educational force corresponds neither with what they ask companies now nor what to ask for in a future "(Carreño, 2014) ${ }^{8}$

5) The success of any enterprise must be approached from the perspective that considers its place in a globalized world and, therefore, limits the ecosystem where it is developed to be fixed globally.

${ }^{8}$ (Carreño, D., 2014). President of General Electric in Sapin and Portugal. Cinco Días. 
Comeche Martínez, J.D., Pascual Ivars, J.V. \& Vivas López, S. (2017) Structure, Effects and Deficiencies of an Entrepreneurial Ecosystem: The Spanish Case. Vol.9(1): 99-118

\section{References}

Audretsch, D. (2007). The entrepreneurial society. Oxford University Press. Oxford.

Audretsch, D.B. \& Fritsch, M. (1994). The geography of firm births in Germany. Regional Studies, VOL. 28, pp. 359-365.

Audretsch, D.B. \&Thurik, R. (2001). Linking entrepreneurship to growth. OECD working papers.

Evans, D. \& Leighton, L. (1990). Small business formation by unemployed and employed workers. Small Business Economics, VOL. 2, pp. 313-330.

Guerrero, M. y Urbano, D. (2011). The Creation and Development of Entrepreneurial Universities in Spain: An Institutional Approach. New York: Nova Pubishers.

Harrison, R.; Mason, C. \& Robson, P. (2010). Determinants of long-distance investing by business angels in the UK. Entrepreneurship and Regional Development, VOL. 22, núm. 2, pp. 113-137.

Marina, J.A. (2013): Ideas. Aprender. Periódico El Mundo, 24 febrero. Madrid.

Mason, C.M. (2006). Informal sources of venture finance. En Parker, S. (ed.): The life cycle of entrepreneurial ventures. International Handbook Serie on Entrepreneurship. USA: Springer, pp. 259-299.

Minola, T.; Minshall, T. \&Giorgina, M. (2008). Acces to external capital for techno startups: Evidences from the UK. Investment Management and Financial Innovations. VOL. 5, núm. 4, pp. 186-199.

OCDE (2011). Financing high-growth firms: The role of angel investors. OCDE Publishing. DOI: 10.1787/9789264118782-en.

Porter, M. \& Kramer, M. (2011). Creating Shared Value. Harvard Business Review. Enhttp://hbr.org/2011/01/the-big-idea-creating-shared-value/ar/pr. 20 diciembre de 2013.

Sarasvathy, S.D. \&Venkataraman, S. (2011). Entrepreneurship as Method: Open Questions for an Entrepreneurial Future. Entrepreneurship, Theory and Practice. January, pp. 113-135.

Sennett, R. (2012). Juntos. Rituales, placeres y política de cooperación. Anagrama.

Thurik, R. (2007). Entrepreneurship, Economic Development and Public Policy. Conferencia pronunciada en el Curso Internacional sobre Actividad Emprendedora y Desarrollo Económico y Social. Universidad de Extremadura. Cáceres. 
GRAPHIC 1. Evolution of the perception of knowledge and skills possession to undertake.

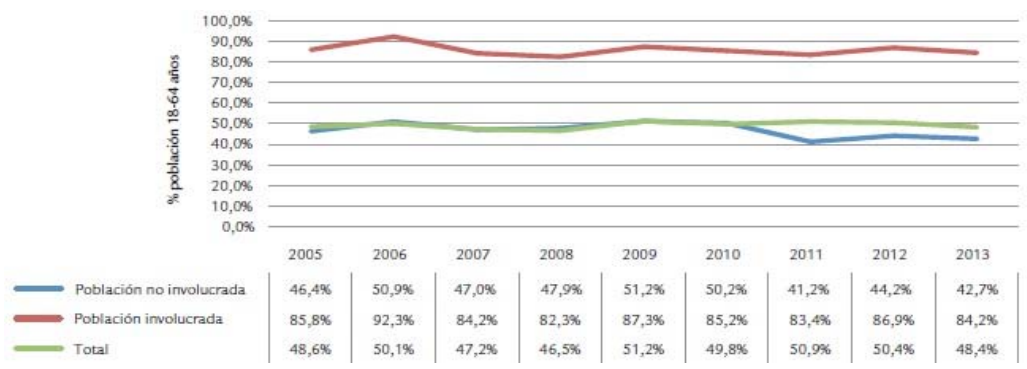

Source: GEM. 2013.

GRAPHIC 2. Evolution of the perception of fear of failure as an obstacle to undertaking.

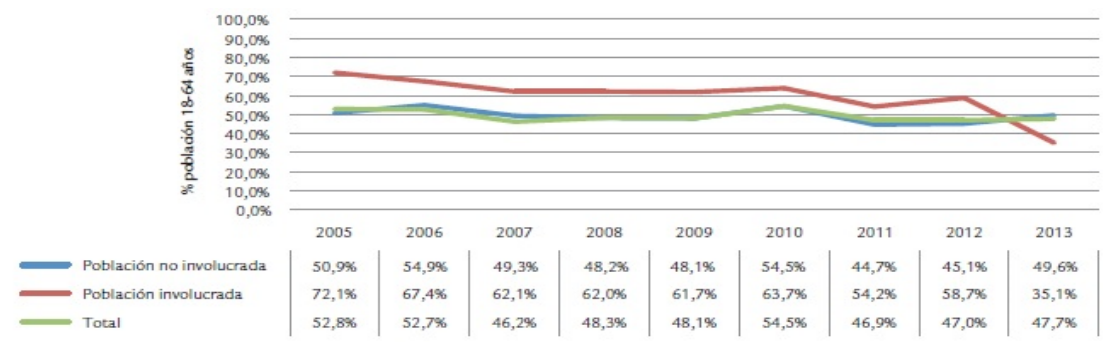

Source: GEM. 2013.

GRAPHIC 3. Evolution of the perception of the existence of reference models.

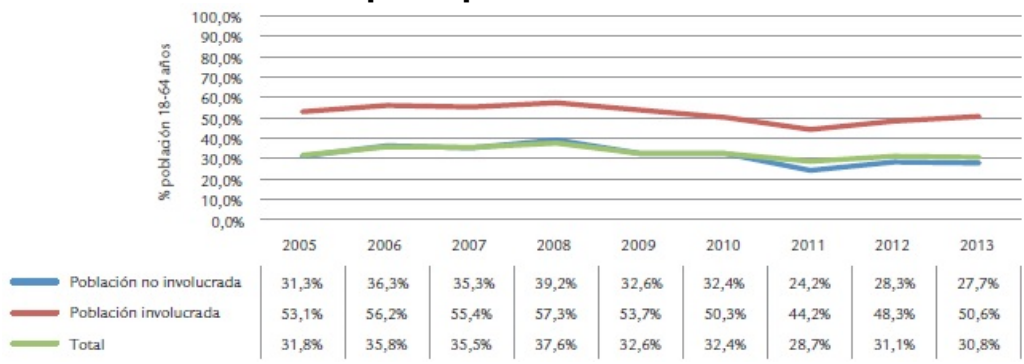

Source: GEM. 2013. 
ANNEX I.

Are we capable of evaluating

risks and assume them?

Do we teach our kids and students to

do so?

Do we accept failure if it comes

from exploring a new path? Or

do we only tolerate when the

paths are known and then we

assume that it is a normal

lerning process?

Do we value the entrepreneurs,

self-employed, bargainer or a

family business follower in the

same way than we value a

multinational manager? Do we

learn from them?

If we have a certain financing

capacity, what do we prefer to

buy our son, a car or give him

money to start a new

entrepreneurial project?

pleased if our son

studies than if he tries to get

ahead an entrepreneurial project?

Do we support him in the same

way?

What do we think about

businessmen? Are thay all

exploiters or speculators? Are

the self-employed the only good

ones?

Do you have professional

experience? Do you have smal

savings and invest in stock

options? Have you considered

Are you capal
business?

supporting entrepreneurial

projects?

Have you got any influence on

other people? Are you a teacher?

Do you encourage other people to

develop their ideas or do you try to

transmit knowledges and strategies

previously evaluated? 
ANNEX II.

\begin{tabular}{|c|c|c|c|c|c|c|}
\hline Environment factors to start a business & Academics & Administration & Consultants & $\begin{array}{l}\text { Managers } \\
\text { Professionals }\end{array}$ & Entrepreneurs & $\begin{array}{l}\text { Total } \\
\text { Mean }\end{array}$ \\
\hline Financing & 2,33 & 2,67 & 3,29 & 2,64 & 2,62 & 2,70 \\
\hline Government Policies: priority support & 2,17 & 2,50 & 2,43 & 2,82 & 2,85 & 2,63 \\
\hline $\begin{array}{l}\text { Government Policies, obstacles reduction: taxes } \\
\text { and burocracy }\end{array}$ & 3,00 & 2,83 & 2,86 & 3,36 & 3,17 & 3,10 \\
\hline $\begin{array}{l}\text { Government Policies: companies promotion, } \\
\text { creation and growth }\end{array}$ & 3,17 & 2,83 & 2,83 & 2,82 & 3,23 & 3,00 \\
\hline Education in primary and secondary teaching & 3,17 & 2,67 & 3,00 & 2,80 & 3,08 & 2,95 \\
\hline Education in University and job training teaching & 3,00 & 2,67 & 2,71 & 3,18 & 3,25 & 3,02 \\
\hline I+D Transfer & 3,33 & 2,83 & 3,29 & 2,73 & 2,77 & 2,93 \\
\hline Commercial and Services Infrastructure & 2,60 & 2,67 & 3,14 & 2,82 & 3,00 & 2,88 \\
\hline Market dynamic & 2,50 & 2,33 & 3,00 & 2,73 & 2,69 & 2,67 \\
\hline Market entry barriers & 3,00 & 2,50 & 2,17 & 2,70 & 2,69 & 2,63 \\
\hline Physic Infrastructure & 2,50 & 2,67 & 3,00 & 2,82 & 2,69 & 2,74 \\
\hline Social and cultural Rules & 2,83 & 2,67 & 2,71 & 3,00 & 3,15 & 2,93 \\
\hline Total mean by experts group & 2,80 & 2,65 & 2,87 & 2,87 & 2,93 & 2,85 \\
\hline
\end{tabular}


ANNEX III.

\section{UBC ECOSYSTEM MODEL > Detailed}

$1 \begin{aligned} & \text { Indirect } \\ & \text { outcomes }\end{aligned}$

Indirect outcomes for society

Economic and social contribution to society generally

2) Direct

Direct Outcomes for actors

outcomes

Contribution to students, academics, HEls and business

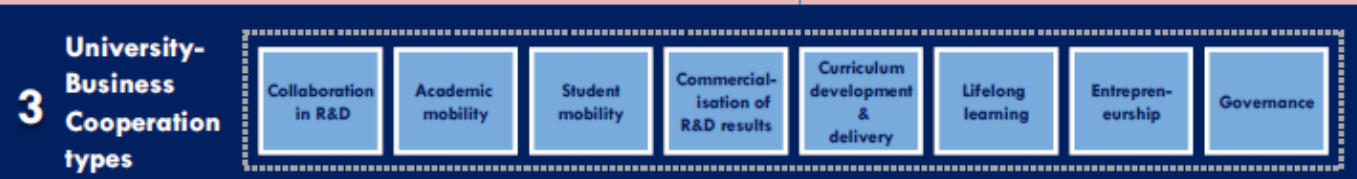

4. Influencing

factors

Supporting

mechanisms

Key

stakeholders

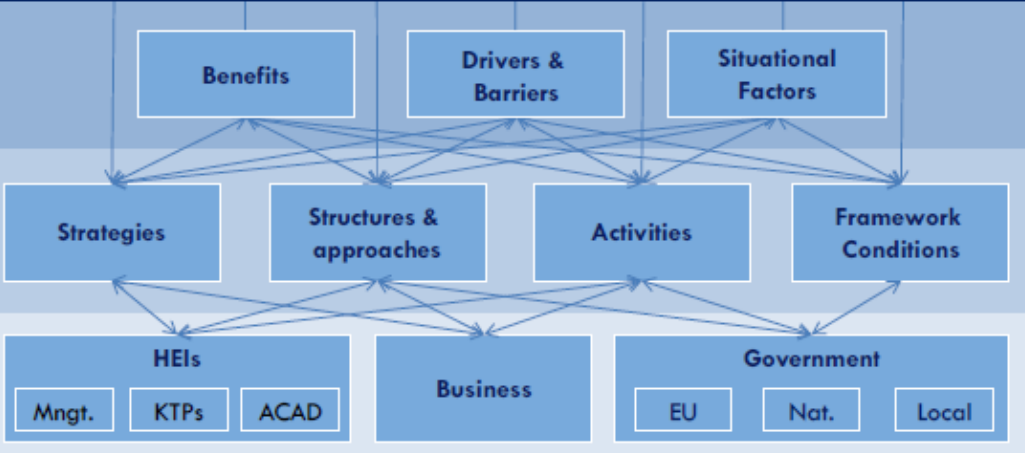

